\title{
Ángeles portadores de coronas en las imágenes de los mártires. Origen del tipo iconográfico
}

\author{
Andrés Felici CASTELL \\ Universidad de Valencia. Departamento de Historia del Arte \\ andres.felici@uv.es
}

\section{Resumen}

Este artículo pretende explicar el origen de las imágenes de los ángeles portando coronas a los mártires, señalando para ello la relación de las coronas con los mártires desde la época paleocristiana, cómo éstas empezaron a ser portadas por ángeles, y los diferentes tipos de coronas que pueden portar según las distintas épocas.

Palabras clave: Ángel; Corona; Mártir.

\section{Angels carrying crowns on the images of martyrs. Origin of the iconographic type}

\begin{abstract}
This article tries to explain the origin of the images of angels carrying crowns to the martyrs; to this end, it points out the relationship of the crowns with the martyrs from Early Christian period, the way these crowns began to be carried by angels, and the different types of crowns they could carry depending on different periods.
\end{abstract}

Key words: Angel; Crown; Martyr. 
Las coronas y las palmas son los atributos que suelen portar los ángeles en las escenas de martirio de los santos, aunque además de éstos, también pueden llevar otros elementos o atributos. Pero no solamente están presentes aquí, ya que pueden aparecer en imágenes conceptuales o en otros episodios narrativos de los mártires diferentes al martirio, incluso también pueden representarse coronando a santos no mártires. En el presente artículo nos centraremos en primer lugar en analizar el símbolo de la corona, partiendo de la Antigüedad Clásica, para ver después cómo el cristianismo vinculó este atributo a sus mártires. A continuación trataremos las diferentes formas de aparecer las coronas junto a los mártires, centrándonos fundamentalmente en las figuras angélicas, prestando especial atención a sus primeras representaciones. Por último veremos los diferentes tipos de coronas que pueden portar los ángeles representados junto a los mártires y su origen.

\section{LAS CORONAS EN EL MUNDO CLÁSICO Y JUDAICO}

La corona tiene un significado amplio y complejo, pero la podríamos definir como el "tocado que hace parecer más alta la cabeza del que lo lleva y junto con el adorno lo eleva por encima del Círculo de sus semejantes"'. En Grecia y Roma la corona tendrá diferentes usos, además del político ${ }^{2}$, ya que se coronaban las estatuas de los dioses, aludiendo a su consagración, los atletas vencedores en juegos de competición, los animales de sacrificio y también la corona podía adquirir un sentido funerario $^{3}$. En definitiva, las coronas estaban vinculadas de una forma u otra a la religión, y de hecho habrá una diosa griega, la diosa Niké -o Victoria para los romanos-, que será la encargada de coronar a los héroes victoriosos, especialmente a los emperadores o generales romanos ${ }^{4}$. Las coronas normalmente eran vegetales, destacando entre ellas la de laurel, adquiriendo así el simbolismo no sólo de la corona, sino también de la planta con la que estaba realizada, aunque las coronas vegetales solían compartir un mismo significado común: la vida, "el poder divino de los árboles" ", de ahí que ya por ejemplo en Egipto, al menos desde la dinastía XVIII, las momias fueran coronadas con guirnaldas de flores, como símbolo de la

1 BIEDERMAN, Hans, Diccionario de símbolos, Barcelona, Paidós, 1996 (1993), p. 125.

2 La "función política" de las coronas se trata más adelante, al hablar de los diferentes tipos de coronas.

3 Sobre el simbolismo de la corona ver CHEVALIER, Jean, Diccionario de los símbolos, Barcelona, Ed. Herder, 1986, pp. 348-350; BIEDERMAN, Hans, (1996), op. cit., pp. 125-127 y CIRLOT, Juan Eduardo, Diccionario de símbolos, Madrid, Ediciones Siruela, 1997, p. 151.

4 Niké según Hesíodo es la hija del titán Palas y la fértil Estigia, sus hermanos son Zelos (Envidia), Crátos (Poder) y Bía (Fuerza), y los cuatro se hallan continuamente cerca de Zeus (Hes. Th. 383 y ss). Sobre la diosa Niké ver HARRAUER, Christine y HUNGER, Herbert, Diccionario de Mitología Griega y Romana, Barcelona, Herder Editorial, 2008 (2006), pp. 584-585 y CONTRERAS VALVERDE, José; RAMOS ACEBES, Gracia; RICO RICO, Inés; Diccionario de la Religión Romana, Madrid, Ediciones Clásicas, 1992, p. 207. La diosa Victoria se convirtió en la divinidad tutelar del emperador Augusto y de sus sucesores, tal y como lo había sido anteriormente de los reyes helénicos, ejerciendo pronto como patrona de las victorias militares (GOODENOUGH, Erwin R., Jewish Symbols in the Greco-Roman Period, Vol. VII, Pantheon Books, Toronto, 1958, p. 140).

5 GOODENOUGH, Erwin R., (1958), op. cit., p. 154. 
inmortalidad, algo que posiblemente influiría en la cultura clásica, amante de disponer figuras de Victorias portadoras de coronas en los sarcófagos ${ }^{6}$.

Por otra parte, las coronas también aparecen en el mundo judío, destacando otro significado más vinculado a la fidelidad y al matrimonio, ya que el recién casado ceñía una diadema a su esposa (Is 61,10-11). Pero durante la época grecorromana el significado clásico de las coronas y la figura de la Niké se introducirán también en la cultura judía. La representación más antigua conocida de una corona en el mundo judío está en las monedas judías acuñadas en tiempos de Juan Hyrcanus (134-104 a. C.), aunque también pueden aparecer coronas en las tumbas ${ }^{7}$. Las figuras de las Nikés portando coronas llegaron a figurar sobre las puertas de algunas sinagogas ${ }^{8}$ y en amuletos 9 .

\section{LAS CORONAS EN EL MUNDO PALEOCRISTIANO. SIGNIFICADO}

En el mundo cristiano, en las coronas asociadas a los mártires, se adoptarán los significados patentes en las tradiciones anteriores, la clásica y la judaica ${ }^{10}$, así podemos decir que las coronas pretenden simbolizar la victoria del mártir ante la muerte, su unión con Cristo -tan estrecha como la de un matrimonio- por la semejanza del martirio con su Pasión y por tanto, al estar unido a Él tan estrechamente, surge una necesidad de veneración ${ }^{11}$, de igual manera que en el mundo clásico eran venerados los dioses y los héroes, aunque en el cristianismo la veneración se realizará de forma diferente ${ }^{12}$. Además de estos significados, no hay que pasar por alto el significado más popular de la corona, como atributo de realeza y poder, como bien explica Isidoro de Sevilla en las Etimologias:

"Los primeros adornos fueron las coronas, signo de la victoria o manifestación del honor real. Se colocaba en la cabeza de los reyes simbolizando a los diferentes pueblos esparcidos por el mundo y con los que se ceñía coronándose como cabeza de los mismos (...). El nombre de corona es debido a que en un principio se danzaba en torno a los altares, y a imitación de este círculo o coro se formó y tomó su denominación la corona" (IsID. orig. 19,30,1-3) ${ }^{13}$.

6 Ibid., p. 153. Esta corona de la vida estaba reservada a los elegidos, cuyas virtudes le habían hecho ganar un sitio en la morada de los inmortales (CUMONT, Franz, Recherches sur le Symbolisme Funéraire des Romains, París, Librairie Orientaliste Paul Geuthner, 1966 (1942), p. 487).

7 GOODENOUGH, Erwin R., (1958), op. cit., p. 149.

8 Así se puede observar hasta en dos templos representados en las pinturas de la sinagoga de Doura Europos (Museo Nacional, Damasco), y según los arqueólogos también figuraron en las enjutas de la puerta de entrada a la sinagoga de Kefr Birim, siendo destruidas en época iconoclasta. Ibid., pp. 135-136.

9 Ibid., p. 136.

10 Los diferentes significados de la corona muchas veces son complementarios, raramente son excluyentes. Ibid., p. 155.

11 "Los bienaventurados mártires, los cuales están tan próximos a nuestro Señor Jesucristo por la imitación de la caridad como por la semejanza de la pasión (...)”. MAGNO, San León, Homilías sobre el año litúrgico, Madrid, BAC, 1969, Homilía 85, p. 364.

12 A principios del siglo III las coronas vegetales eran todavía tan activas simbólicamente en el mundo pagano que algunos cristianos consideraban una profanación el hecho de utilizarlas. GOODENOUGH, Erwin R., (1958), op. cit., p. 161.

13 Madrid, BAC, 2004, p. 1313. 
Este significado de la corona en relación con el poder real también se hará extensible al poder divino, de ahí que en algunas ocasiones se pueda establecer un paralelismo entre ambos poderes, como se aprecia en las Revelaciones de santa Brígida:

"Yo soy Rey coronado, dijo Jesucristo a santa Brígida, y la corona es mi Divinidad, que, como la corona, es redonda y no tiene principio ni fin, tampoco lo tiene mi Divinidad; y como la corona se guarda para el rey que ha de suceder, así mi Divinidad estuvo guardada para que coronase mi Humanidad" (Lib. II, rev. I) ${ }^{14}$.

Desde los inicios de la religión cristiana se establecerá un paralelismo entre los mártires y los atletas, de ahí que el lenguaje cultural cristiano deba mucho al vocabulario del circo $^{15}$, por eso se habla de los "atletas de Dios" 16 , cuyo objetivo final y premio, era obtener la corona, la corona de la vida ${ }^{17}$. En el Nuevo Testamento -especialmente en las cartas de san Pablo y en las apostólicas- se pueden encontrar diversas referencias a la asociación de los mártires con los atletas ${ }^{18}$ : “¿No sabéis que los que corren en el estadio, todos corren, pero sólo uno consigue el premio? Corred de modo que lo conquistéis. Pero los atletas se abstienen de todo, y lo hacen para conseguir una corona corruptible; mas la nuestra, incorruptible" (1 Co 9,24-25) ${ }^{19}$. Debido a eso, no resulta extraño que los mártires cristianos puedan tener el honor de ser representados con coronas de campeones, de hecho el nombre de Esteban, primer mártir, significa coronado, lo cual será utilizado por autores posteriores para acentuar esa vinculación entre el martirio y la corona ${ }^{20}$. Así podemos hablar en este primer momento de un significado de las coronas muy similar al de la tradición clásica, adquirido probablemente por la contaminación del mundo romano.

De esta manera, cuando los mártires empiecen a ser representados en el arte,-- algo que no se dará hasta los siglos III-IV, al iniciarse la extensión de su culto-, normalmente se les representará portando una corona, o siendo coronados, como ya ocurre en los mosaicos de San Apolinar el Nuevo, del siglo VI, en Rávena. Uno de los ejemplos más tempranos, no conservado, pero del cual tenemos una descripción, son unas pinturas murales que representaban la pasión de santa Eufemia, y que fueron descritas por Asterio de Amasea en la homilía sobre santa Eufemia, redactada en el siglo IV, donde se puede leer:

14 Celestiales Revelaciones de Santa Brígida, Madrid, Administración del apostolado de la prensa, 1901, p. 103.

15 GRABAR, André, Las vías de la creación en la iconografía cristiana, Madrid, Alianza Ed., 1985 (1979), pp. 24-25.

16 «Los atletas de Dios fueron enviados allá, como al estadio más grande, desde Egipto y de toda Tebaida, y por su firmísima paciencia en diversos tormentos y géneros de muerte, se ciñeron las coronas preparadas por Dios» (HE VI, 1). CESAREA, Eusebio de, Historia Eclesiástica, Madrid, BAC, 1997, p. 349.

17 Ap 2, 10.

18 Otras citas del Nuevo Testamento donde se nombran las coronas asociadas con el martirio son, por ejemplo: 1 P 5,4; St 1,12; 2 Tm 4,6-8.

19 Este paralelismo entre atletas y mártires también lo reflejan autores posteriores, como TERTULIANO, "Exhortación a los mártires", III, 3, en RUIZ BUENO, Daniel, Actas de los Mártires, Madrid, BAC, 1951, pp. 388-389.

20 HE II 1,1, ed. cit., p. 62; IsID. orig. 7,11,1-4, ed. cit., p. 667; VORÁGINE, Santiago de la, La Leyenda Dorada, Madrid, Alianza Ed., 2002, vol. 1, cap. VIII, p. 60. 
"Después vemos a la Virgen en la prisión: está sentada y sola, con sus vestidos de duelo; invoca a Dios en sus sufrimientos. Mientras reza, aparece por encima de su cabeza el símbolo del martirio que va a sufrir. Muy cerca, en efecto, el pintor ha situado una pira ardiendo que lanza por doquiera llamas rojizas y densas". (Ast.Am., Hom.; PG, XL, 355) ${ }^{21}$.

El "símbolo del martirio que va a sufrir" lo debemos entender aquí como el símbolo que se asociaba al martirio: la corona -además de que este símbolo y no la palma, es más apropiado para estar "por encima de su cabeza"-. Podemos interpretar esta descripción como el primer testimonio visual, del que tenemos constancia, en el que aparece el santo coronado en el momento de su martirio.

\section{DIFERENTES FORMAS DE APARICIÓN DE LAS CORONAS}

En los primeros siglos del cristianismo se pueden distinguir diferentes formas de aparecer las coronas vinculadas a los mártires. Ya hemos señalado un par, por una parte los santos pueden portar sus propias coronas, tipología que probablemente surgiera con las primeras representaciones de los santos, en el siglo IV (Cristo da la corona a los bienaventurados, Roma, catacumba de Domitila), y por otra puede que las coronas aparezcan flotando por encima de su cabeza (Arzobispo Ursino, siglo VI, Rávena, San Apolinar in Classe).

Pero además, como podemos observar en el anterior ejemplo de la catacumba de Domitila, también se puede dar el caso en que la divinidad, personificada en Cristo, haga entrega al santo de la corona, algo que surge a partir del Bajo Imperio ${ }^{22}$.

En época de Constantino se creará una nueva fórmula icónica para definir la jerarquía de poderes, que consistirá en representar al emperador sentado en un trono de oro y la mano de Dios descendiendo para bendecirlo o coronarlo. La tipología de la mano de Dios procedía del arte judío -ya aparece en la sinagoga de Doura-, extendiéndose después al mundo cristiano ${ }^{23}$. Este tipo de representación parece tener relación con las palabras de san Pedro: "Humillaos, pues, bajo la poderosa mano de Dios, para que os ensalce a su tiempo" (1 P 5,6). Se puede señalar, como ejemplo, la medalla que representa a Constantino I coronado por la mano de Dios y sus dos hijos coronados por victorias (ca. 350, Viena, Kunsthistorisches Museum). Esta tipología también se extendería posteriormente a las representaciones de los santos ${ }^{24}$.

Otra curiosa variante consiste en representar la corona portada por una paloma, que simboliza el Espíritu Santo ${ }^{25}$. Resumiendo, podemos llegar a la conclusión que en su origen, las coronas, o están representadas sobre el santo, o son portadas por

21 GRABAR, André, El Primer Arte Cristiano (200-395), Madrid, Aguilar, 1967, p. 287.

22 GRABAR, André, (1985), op. cit., p. 48.

23 Ibid., p. 47.

24 No hay que olvidar que el propio emperador Constantino está canonizado por la Iglesia Ortodoxa.

25 En el cementerio de San Lorenzo en Roma se puede encontrar alguna representación de este tipo. KIRSCHBAUM, Engelberto; JUNYENT, Eduardo y VIVES, José, La Tumba de San Pedro y las Catacumbas Romanas. Los monumentos y las inscripciones, Madrid, BAC, 1954, pp. 297- 299. 
ellos mismos, o son entregadas por alguna de las tres personas de la Trinidad: Padre -la mano divina-, Hijo -Cristo- y Espíritu Santo -la paloma-.

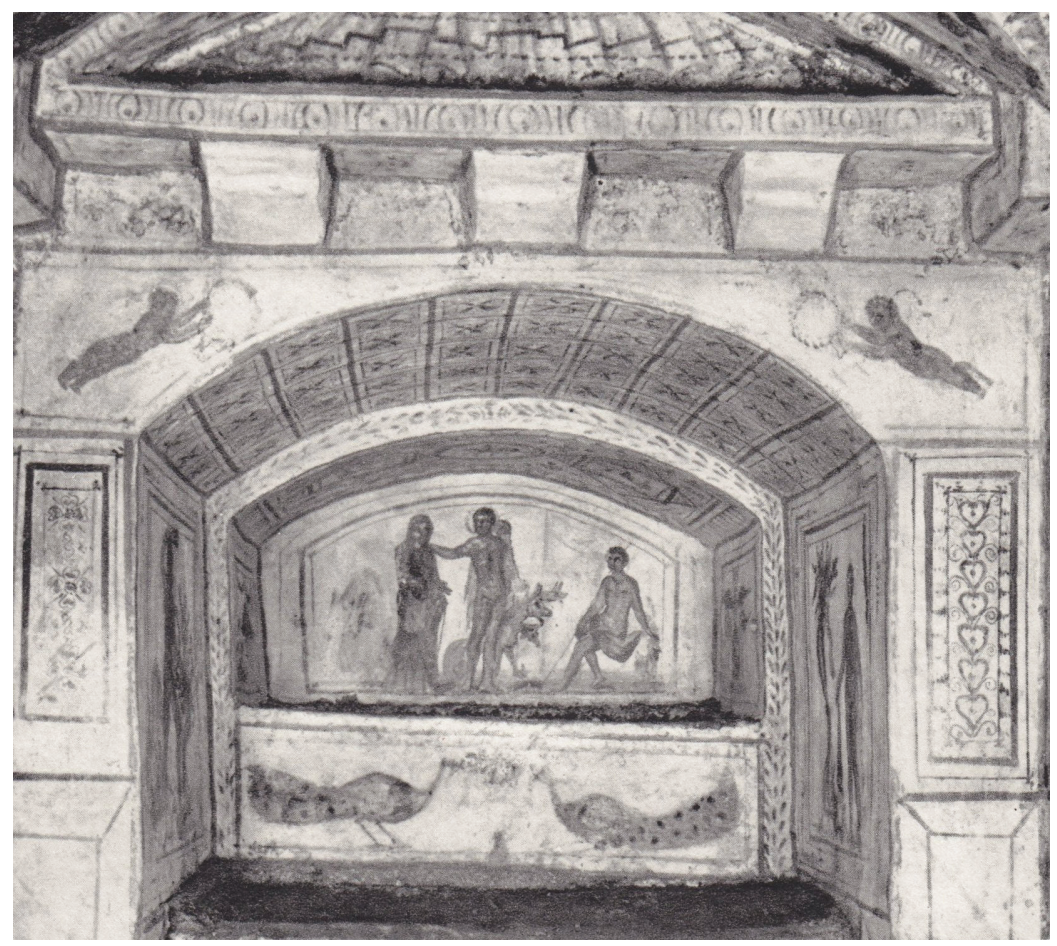

Fig. 1. Alceste ante Hércules y Cerbero, siglo IV, Roma (Italia), catacumba de la vía Latina, sala Norte [tomado de GRABAR, André, El Primer Arte Cristiano (200-395), Madrid, Aguilar, 1967, fig. 229].

El hecho de que sea la Divinidad la que haga entrega de la corona al mártir es algo que viene justificado por las fuentes, y parece responder textualmente a la exclamación de: "¡Así te corone Aquél cuyo nombre has confesado!” ${ }^{26}$. Hay que tener en cuenta, que según algunas narraciones, Cristo, al morir, también fue coronado como "primer mártir" y rey: "E levant-se sanct Miquel, acostà s a sa excelencia, e ficant lo genoll davant sa senyoria, presentà-li de part del seu Pare la vestidura de inmortalitat e la corona molt excellent a ell deguda per la sua alta victoria, e lo sceptre real de la general monarchia" ${ }^{27}$. Como se puede leer, es un ángel, concretamente el arcángel san Miguel, el que corona a Cristo. Desde antiguo se ha hablado de las

26 Carta de Celerino a Luciano, incluida en "Carta de San Cipriano" XXI, I, 3, en RUIZ BUENO, Daniel (1951), op. cit., p. 524.

27 VILLENA, Sor Isabel de, Vita Christi, Valencia, 1497, cap CLXXXVI, fol. 220v. Ed. facsímil de HAUF, Albert. 
"celestes coronas de los mártires" 28 , lo cual parece referirse a coronas procedentes o portadas por seres celestiales, es decir, fundamentalmente ángeles ${ }^{29}$. En el mundo romano los emperadores triunfantes y los héroes eran coronados por Victorias aladas $^{30}$. Por trasposición de esas imágenes, en las catacumbas ya podemos contemplar algunos ángeles, o más bien putti, portando coronas, como sucede en las enjutas de la sala norte de la catacumba de la Vía Latina, en Roma. Pero concretamente, estas figuras aladas se representan en enterramientos paganos, donde hay pintadas escenas como Alceste ante Hércules y Cerbero, o Alceste llorando a Admeto tendido sobre su lecho de muerte (fig. 1). Además, estos putti parecen no estar coronando a nadie en concreto, o al menos directamente, como si fueran más bien elementos decorativos; aunque probablemente su función fuera coronar a los héroes representados o al difunto enterrado. Poco después ya podemos encontrar algunas representaciones donde los ángeles aparecen coronando a Cristo, como ocurre por ejemplo en un sarcófago del siglo V conservado en la catedral de San Salvador, en Aix-en-Provence, donde sobre la escena que representa a Cristo entregando la ley rodeado de los Apóstoles, teniendo a sus pies los dos difuntos, aparecen dos ángeles portando una corona (fig. 2).

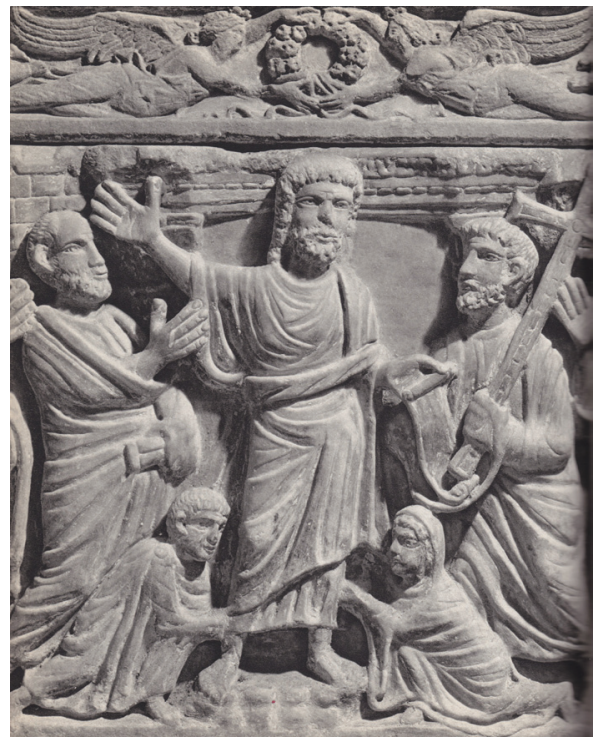

Fig. 2. Cristo dando la ley rodeado de los Apóstoles, siglo V, sarcófago, Aix-en-Provence (Francia), catedral de San Salvador [tomado de GRABAR, André, Las vías de la creación en la iconografía cristiana, Madrid, Alianza Ed., 1985 (1979), fig. 284].

28 San Cipriano, "Tratado De Lapsis", IV, en RUIZ BUENO, Daniel (1951), op. cit., p. 565.

29 Como ya es sabido, y no corresponde aquí tratar, la figura de un ser alado con función de mensajero celeste, tiene un origen más antiguo que la tradición cristiana o clásica (WARD, Laura y STEEDS, Will, Los Ángeles en el Arte, Madrid, Edilupa Ediciones, 2006, p. 6). Sobre el origen iconográfico de los ángeles ver BUSSAGLI, Marco, Storia degli Angeli: Racconto di immagini e di idee, Bolonia, Tascabili Bompiani, 2003.

30 Se puede apreciar un ejemplo en el interior del Arco de Tito, año 81, Roma. 
Sintetizando lo expuesto, podemos indicar que en el mundo paleocristiano pueden aparecer mártires básicamente portando coronas o siendo coronados por alguna de las tres personas de la Trinidad, pero los ángeles no aparecerán coronándolos, aunque sí que puedan aparecer coronando a Cristo. Para encontrar a ángeles coronando a santos habrá que esperar hasta la Edad Media.

\section{LOS ÁNGELES PORTADORES DE CORONAS A LOS MÁRTIRES A PAR- TIR DE LA EDAD MEDIA}

Profundizando más en la figura del ángel portador de corona, una de las primeras veces en la que las fuentes se refieren, indirectamente, a esta tipología, es en el Apocalipsis. En este texto, cuando se describe al primero de los cuatro jinetes se dice: "Miré y había un caballo blanco; y el que lo montaba tenía un arco, se le dio una corona y salió como vencedor, y para seguir venciendo". (Ap 6, 2). En el año 776, Beato, abad de Liébana, escondido en un valle de la cordillera asturiana, escribió un comentario sobre el Apocalipsis. La obra tuvo una amplia difusión y se copió en múltiples ocasiones, iluminándose los diferentes manuscritos con numerosas miniaturas $^{31}$. A la hora de representar a este primer jinete, tal y como se puede observar en el folio 93 recto del Beato conservado en Valladolid (fig. 3), realizado hacia el 980, por encima del jinete arquero planea un ángel que lo corona. El "se le dio", acción citada en el Apocalipsis, se concreta mediante un ángel como portador de dicha corona, constituyendo así uno de los primeros ejemplos medievales en los que podemos observar ángeles coronando, y sabemos que las ilustraciones de los beatos, además de ser unas obras muy copiadas y difundidas, sirvieron de referente para la realización de diversas portadas de iglesias. Es de este modo como, ya en la Baja Edad Media, empezarán a difundirse imágenes de ángeles coronando, que en un principio estarían vinculados a la Virgen, y más tardíamente, también a los santos, ya que todavía continuará siendo frecuente que sea la mano divina la que imponga la corona a los mártires, como ocurre, por ejemplo, en la escena del martirio de san Eustaquio, de la vidriera que narra su leyenda, en la catedral de Chartres, realizada ca. 1200-1210, o en la representación de san Jorge del fresco de los Santos Caballeros en el monasterio egipcio de San Antonio, del siglo XIII.

Pero será en el siglo XIII donde encontremos uno de los primeros ejemplos de ángeles coronando a un santo en el momento del martirio, en concreto en un relieve del tímpano de la portada norte de la catedral de Reims, realizado hacia 1230, donde se representa el martirio de san Nicasio, obispo y mártir local del siglo V, que aparece decapitado y con un ángel de medio cuerpo sobre su cabeza, imponiéndole una corona (fig. 4). Aunque este ejemplo nos puede aparecer casi como un caso aislado, lo cierto es que poco a poco este tipo de imágenes serán utilizadas con mayor frecuencia

31 MÂLE, Émile, El arte religioso del siglo XII al siglo XVIII, México, Fondo de Cultura Económica, 1952 (1945), pp. 10-11. Sobre los Beatos y sus ilustraciones ver WILLIAMS, John, The Illustrated beatus: a corpus of the illustrations of the commentary on the Apocalypse, 5 vols., Londres, Harvey, 1994; YARZA LUACES, Joaquín, Beato de Liébana: manuscritos iluminados, Barcelona, Moleiro, 1998. 


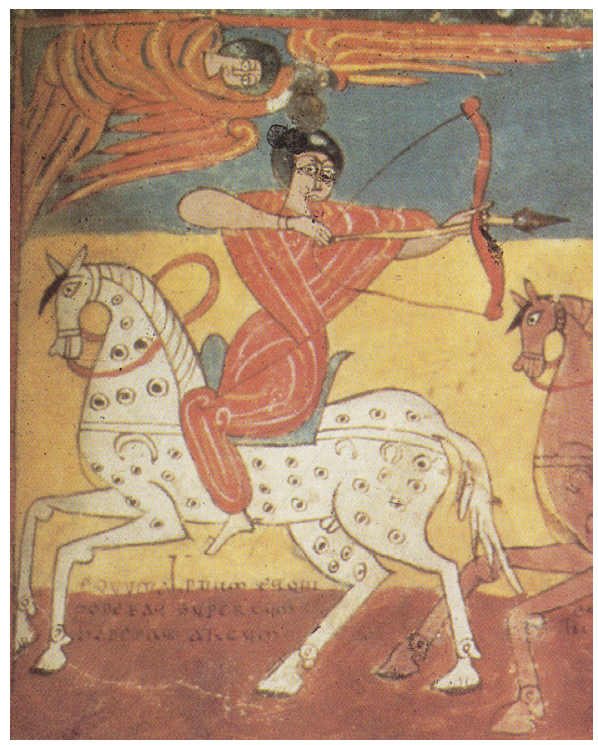

Fig. 3. Cuatro jinetes del Apocalipsis, Oveco, Beato de Valcavado, ca. 980, Valladolid, Biblioteca Universitaria de Santa Cruz, fol 90 r. [tomado de KLUCKERT, Ehrenfried, "La pintura románica", en TOMAN, Rolf (ed.), El Románico. Arquitecura, Escultura, Pintura, Barcelona, Könemann, 2004, p. 445].

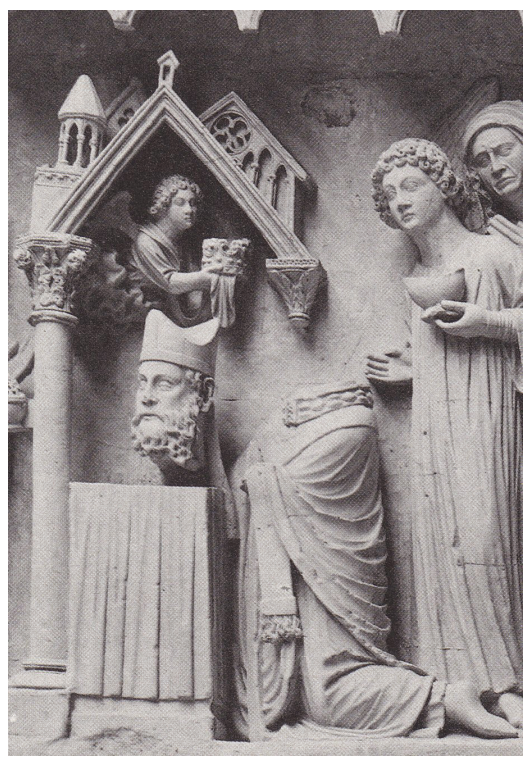

Fig.4. Martirio de san Nicasio, ca. 1230, Reims, Catedral, tímpano de la portada norte [tomado de MÂLE, Émile, El Gótico. La Iconografía de la Edad Media y sus fuentes, Madrid, Ed. Encuentro, 1986 (1889), fig. 136]. 
durante los siglos XIV (Martirio de san Sebastián, Giovanni del Biondo, ca. 1370, Florencia, Museo dell'Opera del Duomo) y XV (Martirio de san Sebastián, Benozzo Gozzoli, 1464-66, San Giminiano, Iglesia de Sant'Agostino), resultando muy frecuentes a partir del siglo XVI, apareciendo normalmente el ángel portando, además de la corona, la palma.

\section{DIFERENTES TIPOS DE CORONAS. LAS CORONAS EN EL MUNDO CLÁSICO}

Un aspecto a tener en cuenta son los diferentes tipos de coronas representadas. Debido a que las coronas de los emperadores romanos no serán las mismas que las de los monarcas medievales, en las representaciones artísticas también se emplearán diferentes coronas, según la época y su significado. En el mundo griego algunos tipos de coronas iban asociados a unos dioses determinados ${ }^{32}$. En el mundo romano también existían diferentes tipos, tal y como recoge Plinio: "No hubo corona más famosa que la de grama en la magestad del pueblo, príncipe de las tierras y premios de gloria y fama. A estas guirnaldas siguieron las coronas de piedras preciosas, las de oro, vallares, murales, rostradas, cívicas y triumphales, las cuales le son en grande manera inferiores. Todas las demás daban los mismos capitanes y emperadores a los soldados, y algunas vezes también a sus colegas y compañeros" (PLin. Nat. 22, 3) ) $^{33}$ Según cuenta el mismo autor, las coronas eran asignadas a las personas por algún reconocimiento especial, y normalmente solían ser coronas vegetales. A éstas se les daba mayor importancia que a las realizadas con metales o piedras preciosas, las cuales también imitaban las formas vegetales ${ }^{34}$. Las coronas tendrían su origen en la mitología, siendo Baco el primero en hacerse una corona, con pámpanos. Los griegos ya las gastarán, utilizando flores de diferentes olores y colores $^{35}$. Las coronas se irán multiplicando, tanto en cantidad -se usarán en convites y juegos- como en significado -las emplearon aquellos que hacían sacrificios para honrar a los dioses, coronando también el animal que sacrificaban- y materiales utilizados, empleándose fundamentalmente las llamadas "plantas coronarias", "éstas eran las que olían bien por razón de su flor o de su hoja o de todo y las que tenían rama apta para atarse o texerse" 36 . Todas las coronas vegetales pretendían tener también un significado simbólico, ya que estaban realizadas de materiales perecederos "para que entiendan que las cosas

\footnotetext{
32 "Las coronas de laurel eran símbolo de Apolo, las de perejil lo eran de Zeus en los Juegos de Nemea (en otras ocasiones, coronas de olivo); las coronas de espigas estaban consagradas a Démeter (lat. Ceres), las de pino a Poseidón, las de hinojo al dios frigio de la agricultura, Sabazios. Coronas de hojas de encina adornaban las sienes de los salvadores de peligro mortal". BIEDERMAN, Hans, Diccionario de Símbolos, Barcelona, Paidós, 1996 (1993), pp. 126-127.

33 Versión española de HERNÁNDEZ, Francisco y DE HUERTA, Jerónimo, en Somolinos D'Ardois, Germán y NOGUÉS, Ma del Carmen (eds.), México, Visor Libros, Universidad Nacional de México, 1999, p. 861.

34 Plin. Nat. 21, 3, en ed. cit., p. 833.

35 Ibid.

36 Intérprete, comentario a PLIN. nat. 21, 3, ed. cit., pp. 833-835.
} 
que con grande hermosura florecen fácilmente se marchitan" (PLIN. Nat. 21, 1) ${ }^{37}$. Plinio también indicará que las coronas se empleaban en el mundo funerario ${ }^{38}$. El mundo cristiano, a priori, simplificará bastante toda esta jerarquía de coronas, siendo muchas veces irreconocible el tipo de planta empleada en las representaciones artísticas. Así, para estudiar los diferentes tipos de coronas en el mundo cristiano éstas las dividiremos fundamentalmente en dos grupos: las coronas vegetales, -haciendo mención aparte a la de laurel-, y las metálicas.

\section{CORONAS DE LAUREL}

Las coronas más antiguas representadas en el mundo cristiano serán las de laurel, llamadas por los romanos "coronas triunfales". Éstas eran las que portaban los emperadores romanos, hasta el Bajo Imperio, apareciendo en representaciones paganas, en diversas ocasiones, sostenidas por Victorias. El laurel se consideraba símbolo del triunfo, de la eternidad -porque se decía que siempre mantenía sus hojas verdes- y de la castidad -porque en el mundo pagano el laurel era consagrado por las vírgenes vestales ${ }^{39}$-. San Isidoro, sobre esta planta, dirá lo siguiente: "El laurel deriva su nombre del vocablo laus -alabanza-; pues con laurel se coronaba, en medio de alabanzas, la cabeza del vencedor (...) nunca pierde su verdor; y ése es el motivo por el que con él se corone a los vencedores. La gente cree además que es el único árbol que resiste a los rayos" (IsiD. Orig. 17,7,2) ${ }^{40}$.

Las fuentes cristianas vincularán el laurel al triunfo de los santos, de ahí que se pueda hablar en el martirio de "recibir el galardón de los laureles eternos"41 e incluso uno de los más venerados mártires del cristianismo, san Lorenzo, su nombre se vincula también a esta planta ${ }^{42}$. En el campo visual, ya en las catacumbas es posible encontrar representaciones del laurel, vinculadas a los mártires, así pueden aparecer palomas, imagen del alma viviente en la paz eterna, con un ramo de laurel en su pico, "como fruto reportado por su victoria en la vida cristiana" ${ }^{43}$. En el ya mencionado sarcófago de Aix-en-Provence, del siglo V (fig. 2), los ángeles coronan a Cristo con una corona de laurel. Con la Edad Media este tipo de corona desparecería prácticamente de la iconografía cristiana ${ }^{44}$, volviendo a reaparecer en el siglo XV, en Italia, con el Renacimiento (San Crisógono a caballo, Michele Giambono, ca. 1450, Venecia, Iglesia de San Trovaso), difundiéndose más a partir del siglo XVI (El martirio de san Mauricio, El Greco, 1580-81, El Escorial, Monasterio de San Lorenzo). En

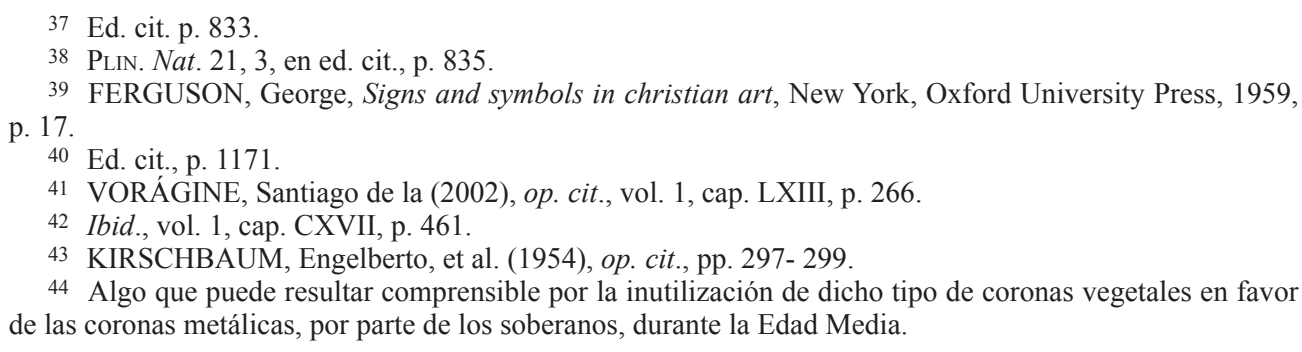

44 Algo que puede resultar comprensible por la inutilización de dicho tipo de coronas vegetales en favor de las coronas metálicas, por parte de los soberanos, durante la Edad Media. 
algunas obras renacentistas, como el Emblematum Liber de Alciato (Augsburg, Steyner, H., 1531), se habla del laurel, vinculándose a la victoria ${ }^{45}$. También en esta época se le dieron nuevos significados a esta planta, así, por ejemplo, Cesare Ripa relaciona el laurel con la virtud ${ }^{46}$.

\section{CORONAS METÁLICAS}

En el siglo IV, con el Bajo Imperio, los emperadores dejaron de utilizar progresivamente la corona de laurel, empleando con mayor frecuencia lo que podemos denominar "diadema imperial" $"$. La corona ya no estaba formada por elementos naturales, sino que se realizaba un aro circular con metales nobles e, incluso también, incrustaciones de piedras preciosas. Es el tipo de corona que podemos ver ya en la citada medalla del Kunsthistorisches Museum de Viena, que representa a Constantino coronado por la mano de Dios, datada en el siglo IV, y estará muy difundida en el arte bizantino, apreciándose ya, en el siglo VI, en la escena del ábside de la iglesia de San Vital, en Rávena, donde Cristo entrega la corona de mártir, en forma de diadema imperial, a san Vital. En algunas fuentes antiguas se habla de las diademas vinculadas a los mártires, como por ejemplo lo hace Eusebio de Cesarea, el cual al citar al cristiano Adaucto, nos dice lo siguiente: "Vencedor en el combate por la fe, fue coronado con la diadema del martirio" 48 . En Occidente, con la Edad Media, este tipo de corona decaerá, volviendo a aparecer ya en el siglo XV, como se puede ver en las tablas laterales del Tríptico de Dresde (Alberto Durero, 1496, Dresde, Gemäldegalerie), y utilizándose en los siguientes siglos, aunque con poca frecuencia.

Posteriormente, a esa diadema se le incorporó una crestería, con florones o puntas con bolas, conformando lo que entendemos más comúnmente como una corona real, el tocado característico de los monarcas medievales. Así, durante la Edad Media será frecuente ver a los santos, incluso a la Virgen y a Cristo, coronados con coronas de oro, muy similares a las utilizadas en la época por los soberanos (Santa Margarita, Maestro de Foces, ca. 1300, Ibieca, iglesia de San Miguel de Foces). Estas coronas pueden diferir unas de otras en pequeños detalles, la ornamentación, el tamaño de la crestería, las incrustaciones de piedras preciosas... incluso algunas parecerán un híbrido entre corona y diadema, por su crestería tan reducida -similares a la corona radiante que coronaba a los dioses y emperadores romanos-, pero de una forma u otra, continuarán utilizándose en el arte hasta prácticamente la actualidad. A veces la decoración de la corona, especialmente el número y el tipo de piedras preciosas, podían tener un significado concreto, dependiendo también de la persona que fuera coronada ${ }^{49}$.

45 Emblema "el laurel", en Los emblemas de Alciato. Traducidos en rimas españolas, 1549, Barcelona, UIB y De Olañeta, J. J., 2003, p. 188.

46 RIPA, Cesare, Iconología, Torrejón de Ardoz, Akal, 1996, p. 430.

47 La diadema "deriva de la simple cinta que rodeaba la frente de los soberanos diadocos (descendientes de Alejandro). Se relaciona, pues, con la corona, y también con el nimbo o aureola". CIRLOT, Juan Eduardo, (1997), op. cit., p. 173.

48 "Los mártires bajo Diocleciano", 11, en RUIZ BUENO, Daniel (1951), op. cit., p. 885.

49 Celestiales Revelaciones de Santa Brígida, ed. cit., lib. IV, rev. LXXXIX, pp. 296-297. 


\section{CORONA VEGETAL O GUIRNALDA DE FLORES}

Por otra parte, hay otra modalidad de corona que podríamos llamar "corona vegetal" o "guirnalda de flores", y que derivaría de las coronas vegetales empleadas en el mundo romano. Aunque pueden existir coronas realizadas con diferentes tipos de plantas o flores, aquí las trataremos todas de forma generalizada, especificando sólo la corona de laurel, que ya se ha tratado anteriormente. El cristianismo hará uso de estas coronas vegetales, así, las flores, y más en concreto las rosas, ya aparecen vinculadas a los mártires desde los primeros siglos del cristianismo ${ }^{50}$, aunque, en el mundo romano, Plinio señala que las rosas "úsanse muy poco en las coronas" (Plin. nat. 21, 4) ) $^{51}$ Por otra parte las coronas de flores, en general, también se relacionaban con los mártires desde los primeros siglos, como dice Eusebio de Cesarea en la Historia Eclesiástica:

"Después de esto, en adelante los géneros de muerte de los mártires eran variadísimos, pues con flores de toda especie y de colores diferentes trenzarán ellos una sola corona para ofrecérsela al Padre, y así era necesario que aquellos generosos atletas, después de haber mantenido una lucha variada y haber vencido en toda la línea, recibieran la gran corona de la inmortalidad" (HE V 1, 36) ${ }^{52}$.

Pese a esta vinculación entre las coronas vegetales y los mártires, en el arte cristiano, cuando aparezcan por primera vez ángeles portando coronas de flores, será coronando a la Virgen. En el siglo XV ya podemos ver a ángeles coronándola con una corona convencional, metálica, decorada con flores (Madonna, Polyptychon des $\mathrm{Hl}$. Gregor, Antonello della Messina, 1473, Mitteltafel, Szene). De hecho desde finales de la Edad Media, los monjes, principalmente, empezaron a relacionar a la Virgen con los perfumes de las flores, y la primavera, asociando a las flores tres virtudes: pudor, caridad y olvido de sí mismo ${ }^{53}$. Indicar también, que las flores siempre se han visto relacionadas con la castidad y la virginidad ${ }^{54}$, y en la literatura de los primeros siglos del cristianismo, cuando se habla de la Virgen, a veces se habla de una corona de virginidad ${ }^{55}$. De hecho, también podemos ver cómo en una revelación a santa Brí-

50 "Martirio de de los santos Santiago y Mariano, y otros muchos", XI, en RUIZ BUENO, Daniel (1951), op. cit., p. 836.

51 Ed. cit., p. 835.

52 Ed. cit., p. 277.

53 MÂLE, Émile (1952), op. cit., p. 117.

54 Molanus, sobre la representación de las vírgenes, señala: "Virginum imaginibus coronam ex floribus conseriam imponimus, quia et virginitatis et florem carpere, et ex eo fauum et mel componere, de quo dicitur, 'Fauns distillans labia tua sponsa: mel et lac sub lingua tua' [Ct 4,11]. Cyprianus etiam virginitatem ipsam florem apellat, in tractatu Demetrianum". MOLANUS, Ioanne., De Historia SS. Imaginum et Picturarum pro vero earum usu contra abusus, Lovaina, 1570, y Gasparem Bellerum, Aquila Aurea, 1617, París, Les éditions du Cerf, 1996, lib. IV, cap. XXIX, p. 454. Cesare Ripa dice que en la representación de la Virginidad "ceñirá su cabeza una corona de flores porque, según dicen los Poetas, la Virginidad no es otra cosa que una flor que, tan pronto como es cogida y arrancada, pierde por completo su gracia y su belleza". op. cit., p. 422.

55 "Aut enim mortua sta Sancta Virgoc sepulta: in gloria dormitio illius est et incastitate exitus eius et in virginate corona" (Epiph.Const., Haer., PG XLII, 737), cit. en BOVER, José Ma , La Asunción de María. Estudio teológico histórico sobre la Asunción corporal de la Virgen a los cielos, Madrid, BAC, 1951, p. 100. Y otro ejemplo lo encontramos en san Cirilo de Alejandría: "Recibe nuestro parabién, María Madre de Dios, tú que 
gida, la propia Virgen se define como una flor: "Y así soy muy parecida a la flor del campo; porque como las abejas sacan miel y dulzura de la flor, y por mucha que le saquen, siempre le queda, igualmente yo puedo alcanzar gracia para todos, quedándome siempre para dar" (Lib. IV, rev. LXIV) ${ }^{56}$. Aunque en las representaciones de la Virgen este tipo de corona fue frecuente, para verla vinculada a los santos habrá que esperar hasta fines del siglo XVI (Santa Domitila con los santos Nereo y Aquileo, Il Pomarancio, ca. 1598-99, Roma, Iglesia de los Santos Nereo y Aquileo) (fig. 5). Pese a que la corona de flores tal vez pudiera ser más característica de aquellos santos que fueron vírgenes, lo cierto es que a partir de los siglos XVI-XVII se usarán las coronas metálicas y las vegetales -tanto de flores como de laurel- indistintamente para cualquier tipo de santo ${ }^{57}$.

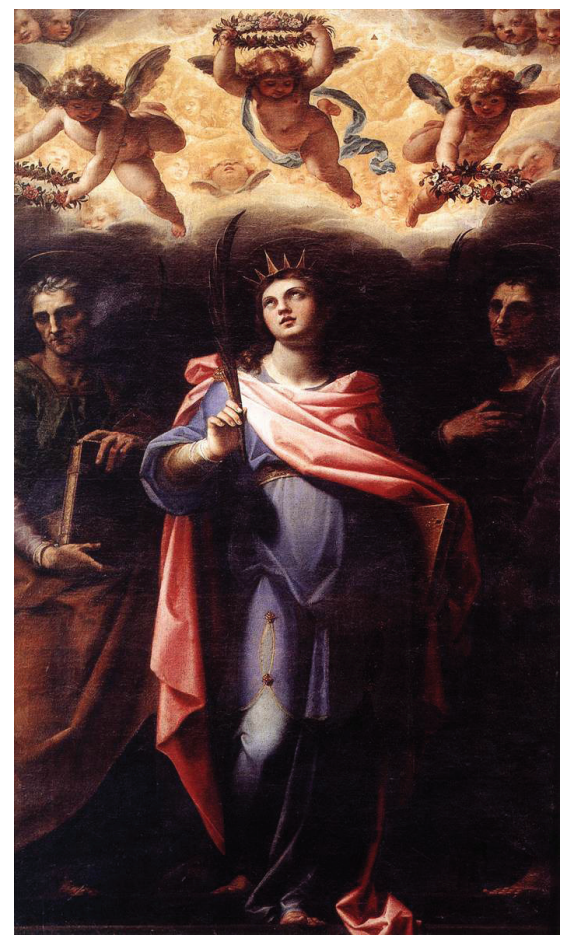

Fig.5. Santa Domitila con los santos Nereo y Aquileo, Il Pomarancio, ca. 1598-99, Roma, Iglesia de los Santos Nereo y Aquileo [tomado de http://www.wga.hu/index1.html].

eres el venerado tesoro de todo el orbe, la inextinguible lámpara, la corona de la virginidad, el indestructible templo, la mansión del Inmenso, la Madre y Virgen" (Cyr.Al., Hom.Diu., PG LXXVII, 992), cit. en BOVER, José $\mathrm{M}^{\mathrm{a}}$ (1951), op. cit., p. 135.

56 Celestiales Revelaciones de Santa Brígida, ed. cit., p. 274.

57 MÂLE, Émile, Arte Religioso del siglo XVII, Italia, Francia, España, Flandes, Madrid, Ed. Encuentro, 1985 (1932), p. 323. En la emblemática de los siglos XVI-XVIII tienen también su impacto los diferentes tipos de guirnaldas o coronas vegetales. Vid. García Mahíques, Rafael, Empresas sacras de Núñez de Cepeda, Madrid, Tuero, 1988, pp. 56-57. 


\section{CONCLUSIÓN}

La corona es un elemento muy estrechamente ligado a la palma, tanto en el mundo clásico como en el cristiano. Pese a eso, en las primeras imágenes cristianas no aparecerán ángeles portando estos dos elementos ${ }^{58}$, ya que los dos tenían prácticamente el mismo significado en la mentalidad cristiana, en cambio en el mundo romano no era infrecuente que las Nikés portaran ambos atributos ${ }^{59}$. Por eso habrá que esperar prácticamente hasta el Renacimiento para que los artistas contemplen la tipología de las Victorias romanas y la adapten a los ángeles cristianos, siendo representados así con ambos atributos ${ }^{60}$.

El fin último de las coronas y las palmas era mostrar el triunfo del mártir, pero para representar ese triunfo también se podía recurrir a los atributos del martirio del santo ${ }^{61}$, como de hecho se realizó con gran frecuencia. Será posteriormente, especialmente en el Barroco, cuando, para acentuar más el triunfo de los mártires, los "campeones de la fe católica", se los representará con los atributos de su martirio o padeciéndolo, con ángeles, o toda la corte celestial, portando coronas y palmas. De ahí que sea en esta época cuando este tipo de ángeles tenga una gran proliferación.

\footnotetext{
58 Aunque en la literatura de los primeros siglos ya se puede encontrar la vinculación de ambos elementos, San Cipriano, De bono patientiae, en RUIZ BUENO, Daniel (1951), op. cit., p. 171.

59 Un ejemplo lo encontramos en los relieves de las enjutas del Arco de Septimio Severo en Leptis Magna, de los siglos II-III.

60 Un ejemplo puede ser el Martirio de san Sebastián, Pinturicchio, última década del siglo XV, Vaticano, Sala de los Santos del Apartamento Borgia.

61 "A ciascuno di questi santi è stata attribuita la sua insegna non solo per distinguerlo dagli altri, ma come segno della sua gloria e del suo trionfo". PALEOTTI, Gabriele, Discorso intorno alle immagini sacre e profane, Ciudad del Vaticano, Librería Editrice Vaticana, 2002 (1582), lib. II, cap. XXIX, 3, pp. 182-183.
} 